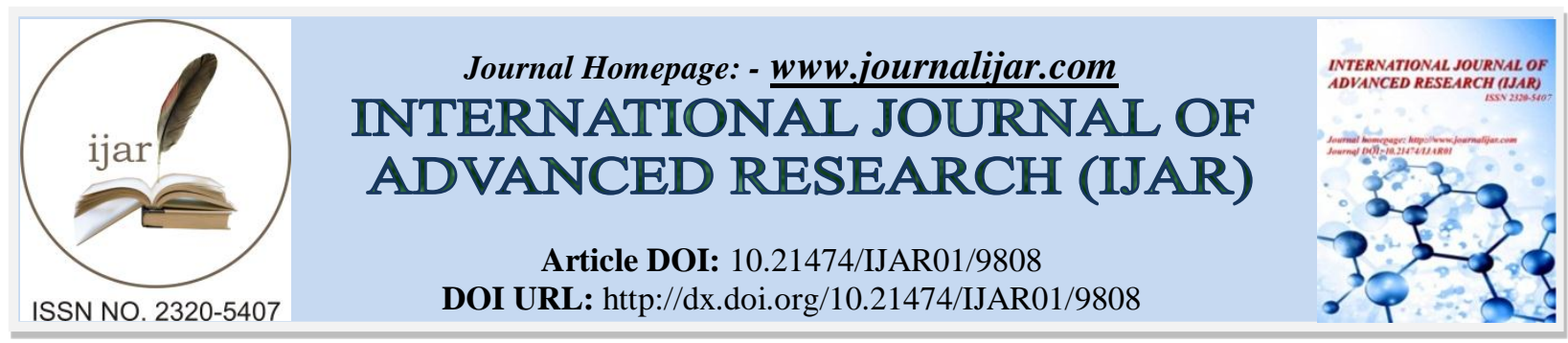

RESEARCH ARTICLE

\title{
COMPARATIVE STUDY BETWEEN SLEEVE GASTRECTOMY WITH SINGLE ANASTOMOSIS DUODENO-ILEAL B YPASS AND MINI-GASTRIC BYPASS IN MANAGEMENT OF MORBID OBESITY.
}

\begin{abstract}
Yasser Ali Elsayed, Atif Mohamed Abd El -Latif, Tamer Youssef Mohamed, Hesham Mohamed Abdalla and Mohamed khidr Mohamed.
\end{abstract}

\section{Manuscript Info}

Manuscript History

Received: 02 August 2019

Final Accepted: 04 September 2019

Published: October 2019

\section{Abstract}

Background: Many surgical procedures have been proposed for management of morbid obesity. This study was conducted aiming to compare between the outcomes of open loop duodenal switch (DS) and laparoscopic minigastric bypass (MGB) procedures.

Study type: Prospective comparative study.

Patient and methods: 50 patients were included in the study. They were divided into 2 groups; group 1 included 25 patients who underwent open loop DS while group 2 included 25 patients who underwent laparoscopic minigastric bypass. All patients were subjected to complete history taking, physical examination, and routine investigations. Lipid profile and diabetic status were also assessed. After discharge, patients were followed up at 3, 6, and 12 months after the procedures where weight, BMI, and laboratory investigations were assessed in each visit.

Results: The mean age of the included patients was 34.76 for the DS group and 36.0 years for MGB group. In each group, 20 females (80\%) as well as 5 males (20\%) were included. The mean BMI of the included patients was 52.59 and $51.6 \mathrm{~kg} / \mathrm{m}^{2}$ for both groups respectively. No significant difference was detected between the two groups regarding preoperative albumin, lipid profile, or HbA1c levels. Mean patient weight decreased postoperatively to $128.92,117.63$, and $105.28 \mathrm{~kg}$ after 3, 6, and 12 months in DS group. In the MGB group, mean weight decreased to $133.75,124.14,117.16 \mathrm{~kg}$ at the same time intervals respectively. BMI decreased to $48.45,43.01$, and $38.27 \mathrm{~kg} / \mathrm{m}^{2}$ in DS group while in the other group it showed a decrease down to 49.35 , 46.89 , and $42.33 \mathrm{~kg} / \mathrm{m}^{2}$ at the previously reported time intervals in order of speech. It was evident that 6- and 12-month changes were significantly better in Ds group compared to MGB group ( $\mathrm{p}<0.05$ ).

Conclusion: Based on the results of the current study, it was evident that both open loop duodenal switch and laparoscopic minigastric bypass procedures are effective in the management of morbid obesity and its related comorbidities. However, loop DS operation is more effective in weight loss compared to MGB.

Copy Right, IJAR, 2019,. All rights reserved. 


\section{Introduction:-}

Over the past few decades, many studies have reported that there has been an increased incidence in obesity. With no signs of slowing down, this incidence has reached epidemic levels in USA and other countries around the globe ${ }^{1}$.

According to a representative sample of nearly 14,000 individuals in the National Health and Nutrition Examination Survey. The prevalence of obesity among adults in the USA, defined as body mass index $(\mathrm{BMI}) \geq 30 \mathrm{~kg} / \mathrm{m}^{2}$ [calculated as weight (kilograms) divided by the square of the height (meter)] increased from $13 \%$ in 1962 to $32 \%$ in 2004. with $3 \%$ of men and $7 \%$ of women classified as being severely obese $\left(\mathrm{BMI} \geq 40 \mathrm{~kg} / \mathrm{m}^{2}\right)$ in the most recent estimate $^{2}$.

Disproportionate increase in the prevalence of super obesity $\left(\mathrm{BMI} \geq 50 \mathrm{~kg} / \mathrm{m}^{2}\right)$ is evident when specifically examining trends in severe obesity, with a nearly tenfold increase in the prevalence of super obesity between 1986 and 2005. as compared to a twofold increase in obesity $\left(B M I \geq 30 \mathrm{~kg} / \mathrm{m}^{2}\right)$ and fivefold increase in severe obesity $\left(\mathrm{BMI} \geq 40 \mathrm{~kg} / \mathrm{m}^{2}\right)$ during this period ${ }^{3}$.

Obesity represents the most serious health problem in $21^{\text {th }}$ century. Besides, it is one of the most important preventable causes of death according to multiple reports. Multiple diseases have been linked to obesity including type II diabetes (T2D), hypertension, coronary heart disease, dyslipidemia, metabolic syndrome X, some forms of cancer, osteoarthritis, and psychosocial problems ${ }^{4}$.

Multiple medical and surgical ways have been proposed to treat obesity. Medical methods include exercise, diet, as well as some medications like phentermine and more recently combination drugs containing phentermine and topiramate. Nevertheless, these options achieve modest weight loss and are difficult to sustain over the long term. Conversely, bariatric surgery can achieve sustained and more effective weight loss. In addition, it leads to resolution of many obesity related comorbidities ${ }^{5}$

As it achieves better short and long term results, bariatric surgical procedures are considered the best current treatment option for severe obesity ${ }^{6}$.

Being a modification of the biliopancreatic diversion procedure originally described by Scopinaro, duodenal switch (DS) is a bariatric procedure that depends mainly on malabsorption. The main differences between the two procedures are preservation of the pylorus, sleeve gastrectomy (SG) to reduce the gastric reservoir, and a common channel with a length of $100 \mathrm{~cm}$ rather than $50 \mathrm{~cm}$ as described originally by Scopinaro ${ }^{7}$.

Food absorption is decreased by the diversion of biliopancreatic secretions in this procedure. In addition, rapid delivery of nutrients into the terminal ileum stimulates the secretion of many hormones that play an important role in obesity improvement ${ }^{8}$.

Single Anastomosis Duodeno-Ileal bypass with Sleeve gastrectomy" or SADI-S is a modification of DS operation at which only one anastomosis is performed. Decreasing the number of anastomoses decreases the incidence of postoperative anastomotic complications like leakage or strictures. Moreover, operative time is also decreased ${ }^{9}$.

Additionally, pyloric preservation decreases the incidence of dumping syndrome after duodenal diversion ${ }^{10}$.

The RYGB generally is one of the best-established procedures in bariatric surgery. Nevertheless, the failure rate with weight regain due to a dilatation of the gastric pouch, gastro-jejunostomy and proximal jejunum is up to $35 \%$. Recently, bile reflux was identified as one important cause of postoperative pain. Again, a postpyloric reconstruction seems tempting for this procedure ${ }^{11}$.

Laparoscopic mini gastric bypass (MGB) (omega gastric bypass (OGB)) is newer bariatric procedures ${ }^{12}$. MGB has been reported to be a very safe, simple, and effective bariatric procedure. All the reports published to date have been very encouraging 13

Various studies of the MGB have reported excellent results with the additional benefits of being relatively simple to perform and associated with low complication rates ${ }^{14}$. 
The MGB was designed to overcome limitations of the RYGB and improve its outcomes. The goal was to create a powerful operation that was simple with minimal complications, a short learning curve, a high degree of efficacy, and that was easily reversed or revised ${ }^{15}$.

This study was conducted to compare between the outcomes between loop duodenal switch and minigastric bypass in the management of morbid obesity.

\section{Patients and methods:-}

Study design

This a prospective study including morbid obese patients who presented at Mansoura University Hospital from January 2016 to January 2018. The study was approved by the local ethical committee.

\section{Patient sample}

Fifty patients with morbid obesity were included in the study. They were divided into two equal groups; group 1 who underwent open loop duodenal switch procedure while group 2 who underwent laparoscopic minigastric bypass procedure. Inclusion criteria included age between $18-60$ years, BMI $>40 \mathrm{~kg} / \mathrm{m}^{2}$, motivated patients who are free of significant psychological diseases, and general fitness for anesthesia and operation.

Patients who were below 18 years old, having lack of motivation, mental incompetence, drug addiction, malignancy, active gastric or duodenal ulceration, or generalized severe systemic disease that precludes general anesthesia were excluded from our study. Moreover, patients who refused to commit to long-term follow up were also excluded.

\section{Patient preparation}

All patients were subjected to complete medical history taking, thorough physical examination, and routine laboratory investigations. Serum cortisol and thyroid profile were also ordered to exclude hormonal disturbances that cause obesity. Additionally, echocardiography, ECG, as well as pulmonary function tests were also ordered. Upper GI endoscopy was performed for all patients to exclude the presence of hiatus hernia or significant reflux disease. Blood glucose level as well as HbA1c were also tested to assess the efficacy of diabetic control before operation.

\section{Operative procedure}

\section{Open loop duodenal switch procedure}

Under general anesthesia, all patients were explored via upper midline incision. After division of short gastric vessels, sleeve gastrectomy was performed by staples over 36-F bougie. Furthermore, the entire staple line was oversewn with continuous imbricating sutures.

Duodenum was transected at the level of gastroduodenal artery and the distal stump was oversewn by absorbable sutures. After identification of ileocecal valve, an end to side hand sewn anastomosis was created between proximal duodenal stump and ileal loop $200-250 \mathrm{~cm}$ proximal to ileocecal valve. Methylene blue test was used to test for anastomotic and staple line leakage.

If the patient had gall stones, cholecystectomy was performed at the same session. Tube drain was inserted near to duodeno-jejunal anastomosis. Finally, abdominal wall was closed in layers.

\section{Laparoscopic minigastric bypass}

After abdominal insufflation and insertion of the four ports under visual guidance of the laparoscopy, the left liver lobe was retracted. Using harmonic scalpel or ligasure, a small window was created at the lesser omentum at the level of incisura adjacent to the lesser gastric curve. After creating a window to the lesser sac, an endostapler was used to create the horizontal border of the gastric pouch after bougie insertion. If there were any adhesions hindering the stapler way to the cardia, it was dissected before completion of the gastric pouch.

The vertical part of the gastric pouch was usually created by two or three cartridges. After that, the transverse mesocolon was retracted upwards to make good view of the DJ flexure. Gastrojejunostomy was created between the gastric pouch and the jejunum about $250-300 \mathrm{~cm}$ away from DJ. The anastomosis was created by blue cartridge and the remaining defect was closed by Vicryl 3/ 0 sutures. A methylene blue test was performed after closure of the afferent and afferent bowel loops. 


\section{Follow up}

All patients were followed three weeks, three months, six months, and one year postoperatively. Patients were assessed for complications, weight, BMI, and laboratory investigations including CBC, liver and renal function tests, lipid profile, blood glucose levels, calcium, and HbA1c.

\section{Statistical analysis:-}

The study was performed at $95 \%$ level of significance and power of $80 \%$. The collected data were coded, processed and analysed using the SPSS (Statistical Package for Social Sciences) version 22 for Windows® (SPSS Inc, Chicago, IL, USA). Qualitative data was presented as number (frequency) and Percent. Normally distributed data was presented as mean $\pm \mathrm{SD}$ and range $(\min -\max )$. Paired t-test was used for comparison within groups. Student t-test was used to compare between two groups. $\mathrm{P}<0.05$ was considered to be statistically significant.

\section{Results:-}

\section{Demographic data}

The mean age of the included patients was 34.76 and 36.0 years for DS and MGB groups respectively. In each group, 20 females $(80 \%)$ as well as 5 males $(20 \%)$ were included. The mean BMI of the included patients was 52.59 and $51.6 \mathrm{~kg} / \mathrm{m}^{2}$ for both groups respectively. When dividing each group according to BMI, each group included 15 patients $(60 \%)$ with BMI between $50-60 \mathrm{~kg} / \mathrm{m}^{2}$, and the remaining 10 patients $(40 \%)$ were having BMI of $40-50$ $\mathrm{kg} / \mathrm{m}^{2}$. No significant difference was detected between the two study groups regarding demographics $(\mathrm{p}>0.05)$. These data are illustrated at table (1).

Table 1:-Demographic data in the two studied groups.

\begin{tabular}{|c|c|c|c|}
\hline Items & $\begin{array}{l}\text { Open loop duodenal switch } \\
n=25\end{array}$ & $\begin{array}{c}\text { Mini gastric bypass } \\
\mathrm{n}=25\end{array}$ & $\mathrm{P}$ value \\
\hline Age (years) & $34.76 \pm 9.72$ & $36 \pm 7.29$ & 0.622 \\
\hline \multicolumn{4}{|l|}{ Sex } \\
\hline -Female & $20(80 \%)$ & $20(80 \%)$ & \multirow[t]{2}{*}{1} \\
\hline -Male & $5(20 \%)$ & $5(20 \%)$ & \\
\hline Weight $(\mathrm{kg})$ & $146.56 \pm 15.06$ & $140.69 \pm 19.11$ & 0.112 \\
\hline $\operatorname{BMI}\left(\mathrm{Kg} / \mathrm{m}^{2}\right)$ & $52.59 \pm 3.99$ & $51.6 \pm 2.81$ & 0.454 \\
\hline \multicolumn{4}{|c|}{ Categories of BMI } \\
\hline $40-50 \mathrm{~kg} / \mathrm{m}^{2}$ & $10(40 \%)$ & $10(40 \%)$ & \multirow[t]{2}{*}{1} \\
\hline $50-60 \mathrm{~kg} / \mathrm{m}^{2}$ & $15(60 \%)$ & $15(60 \%)$ & \\
\hline
\end{tabular}

\section{Comorbidities}

Regarding comorbidities, DS group included 15 patients with diabetes (60\%) as well as 12 patients with hypertension (48\%). On the other hand, MGB group included 10 diabetic patients (40\%) in addition to 9 hypertensive patients (36\%). The remaining comorbidities are shown in the following table. No significant difference was detected between the two groups regarding pre-existing comorbidities.

Furthermore, 4 patients presented with gall bladder stones 1 case in the SADI-S group and underwent cholecystectomy with the duodenal switch and 3 patients in the MGB group 2 of them underwent cholecystectomy with the operation. These data are illustrated at table (2).

Table 2:-Associated comorbidities in the two studied groups.

\begin{tabular}{|l|c|c|c|}
\hline \multicolumn{1}{|c|}{ Items } & $\begin{array}{c}\text { Open loop duodenal switch } \\
\mathrm{n}=25\end{array}$ & $\begin{array}{c}\text { Mini gastric bypass } \\
\mathrm{n}=25\end{array}$ & P value \\
\hline Diabetes & $15(60 \%)$ & $10(40 \%)$ & 0.085 \\
\hline HTN & $12(48 \%)$ & $9(36 \%)$ \\
\hline OSA & $2(8 \%)$ & $3(12 \%)$ \\
\hline Arthritis & $1(4 \%)$ & $1(4 \%)$ & $3(12 \%)$ \\
\hline Gall stones & $1(4 \%)$ & & \\
\hline
\end{tabular}




\section{Preoperative laboratory parameters}

When it comes to the preoperative laboratory parameters, no significant difference was detected between the two groups regarding albumin, lipid profile, or HbA1c levels. These data are shown at table (3).

Table 3:-Preoperative laboratory parameters in the two studied groups.

\begin{tabular}{|l|c|c|c|}
\hline \multicolumn{1}{|c|}{ Items } & $\begin{array}{c}\text { Open loop duodenal switch } \\
\mathrm{n}=25\end{array}$ & $\begin{array}{c}\text { Mini gastric bypass } \\
\mathrm{n}=25\end{array}$ & P value \\
\hline Albumin & $4.19 \pm 0.33$ & $4.29 \pm 0.48$ & 0.522 \\
\hline LDL & $164.27 \pm 40.19$ & $159.37 \pm 41.25$ & 0.132 \\
\hline HDL & $36.98 \pm 10.88$ & $38.94 \pm 9.18$ & 0.108 \\
\hline TGs & $204.73 \pm 23.10$ & $208.22 \pm 37.38$ & 0.175 \\
\hline Cholesterol & $237.92 \pm 83.37$ & $246.18 \pm 34.86$ & 0.096 \\
\hline HbA1C & $9.41 \pm 2.12$ & $9.92 \pm 1.87$ & 0.428 \\
\hline Bilirubin & $0.79 \pm 0.14$ & $0.71 \pm 0.11$ & 0.305 \\
\hline Calcium & $9.26 \pm 2.03$ & $9 \pm 1.39$ & 0.539 \\
\hline
\end{tabular}

\section{Operative time}

A shown in table (4), operative time was significantly longer for MGB group (155.08 vs. 71.12 minutes for DS group $-\mathrm{p}<0.001)$.

Table 4:-Operative time in the two studied groups.

\begin{tabular}{|c|c|c|c|}
\hline Items & $\begin{array}{c}\text { Open loop duodenal switch } \\
\mathrm{n}=25\end{array}$ & $\begin{array}{c}\text { Mini gastric bypass } \\
\mathrm{n}=25\end{array}$ & $\begin{array}{c}\text { Test of } \\
\text { significance }\end{array}$ \\
\hline Operative time (minutes) & $71.12 \pm 8.13$ & $155.08 \pm 51.51$ & $<0.001^{*}$ \\
\hline
\end{tabular}

BMI and laboratory changes 3 months after operation

At 3-month follow up, BMI has decreased down to 48.45 and $49.35 \mathrm{~kg} / \mathrm{m}^{2}$ for both groups respectively. Both lipid profile and HbAlc showed improvement in both groups. Nevertheless, no significant difference was detected between the study groups regarding these parameters $(\mathrm{p}>0.05)$. These data are shown at table (5).

Table 5:-Weight, BMI and laboratory parameters in the two studied groups (at 3 months postoperative).

\begin{tabular}{|l|c|c|c|}
\hline \multicolumn{1}{|c|}{ Items } & $\begin{array}{c}\text { Open loop duodenal switch } \\
\mathrm{n}=25\end{array}$ & $\begin{array}{c}\text { Mini gastric bypass } \\
\mathrm{n}=25\end{array}$ & P value \\
\hline Body weight $(\mathrm{kg})$ & $128.93 \pm 5.39$ & $133.75 \pm 3.48$ & 0.124 \\
\hline BMI $\left(\mathrm{kg} / \mathrm{m}^{2}\right)$ & $48.45 \pm 3.48$ & $49.35 \pm 2.77$ & 0.545 \\
\hline Albumin & $4.21 \pm 0.27$ & $4.03 \pm 0.34$ & 0.635 \\
\hline LDL & $145.28 \pm 37.09$ & $147.32 \pm 44.18$ & 0.239 \\
\hline HDL & $45.26 \pm 13.05$ & $43.63 \pm 12.42$ & 0.122 \\
\hline TGs & $184.17 \pm 9.65$ & $187.81 \pm 45.51$ & 0.211 \\
\hline Cholesterol & $177.14 \pm 29.77$ & $181 \pm 33.93$ & 0.159 \\
\hline HbA1C & $7.49 \pm 1.34$ & $7.16 \pm 1.20$ & 0.428 \\
\hline Bilirubin & $0.84 \pm 0.13$ & $0.75 \pm 0.11$ & 0.235 \\
\hline Calcium & $9.48 \pm 0.81$ & $9.67 \pm 0.74$ & 0.370 \\
\hline
\end{tabular}

\section{BMI and laboratory changes 6 months after operation}

After 6 months, DS groups showed a significant decrease in BMI when compared to MGB (43.01 vs. $46.89 \mathrm{~kg} / \mathrm{m}^{2}-$ $\mathrm{p}=0.044)$. Additionally, HbA1C levels showed a significant decrease in DS group when compared to the other group $(6.12$ vs $6.96 \%-p=0.042)$. Although no significant changes were detected between both groups regarding lipid profile, DS patients showed more improvement in HDL levels (51.27 vs. $44.39 \mathrm{mg} / \mathrm{dl}-\mathrm{p}=0.047)$. Serum calcium and bilirubin levels did not differ significantly between the two groups. Data are shown at table (6).

Table 6:-Weight, BMI and laboratory parameters in the two studied groups (at 6 months postoperative).

\begin{tabular}{|l|c|c|c|}
\hline \multicolumn{1}{|c|}{ Items } & $\begin{array}{c}\text { Open loop duodenal switch } \\
\mathrm{n}=25\end{array}$ & $\begin{array}{c}\text { Mini gastric bypass } \\
\mathrm{n}=25\end{array}$ & $\begin{array}{c}\text { Test of } \\
\text { significance }\end{array}$ \\
\hline Weight $(\mathrm{kg})$ & $117.63 \pm 7.39$ & $124.14 \pm 5.27$ & $0.022^{*}$ \\
\hline
\end{tabular}




\begin{tabular}{|l|c|c|c|}
\hline BMI $\left(\mathrm{Kg} / \mathrm{m}^{2}\right)$ & $43.01 \pm 3.98$ & $46.89 \pm 2.77$ & $0.044^{*}$ \\
\hline Albumin & $4.35 \pm 0.28$ & $4.15 \pm 0.42$ & 0.937 \\
\hline LDL & $133 \pm 30.73$ & $136.47 \pm 34.66$ & 0.172 \\
\hline HDL & $51.27 \pm 11.28$ & $44.39 \pm 9.37$ & $0.047^{*}$ \\
\hline TGs & $153.97 \pm 34.28$ & $157.70 \pm 39.86$ & 0.316 \\
\hline Cholesterol & $155.28 \pm 27.88$ & $158.28 \pm 42.28$ & 0.389 \\
\hline HbA1C & $6.12 \pm 1.34$ & $6.96 \pm 1.06$ & $0.042^{*}$ \\
\hline Bilirubin & $0.75 \pm 0.16$ & $0.67 \pm 0.09$ & 0.729 \\
\hline Calcium & $9.69 \pm 0.32$ & $9.35 \pm 0.19$ & 0.384 \\
\hline
\end{tabular}

BMI and laboratory changes 12 months after operation

At 12-month follow up, BMI decreased significantly in DS group when compared to MGB group (38.27 vs. 42.33 $\left.\mathrm{kg} / \mathrm{m}^{2}-\mathrm{p} 0.029\right)$. Additionally, HDL levels were significantly higher for DS patients (62.38 vs. $55.25 \mathrm{mg} / \mathrm{dl}-\mathrm{p}=$ $0.011)$. HbA1C was significantly lower for DS group as well $(\mathrm{p}=0.008)$. Regarding albumin, bilirubin, calcium, and other lipid profile parameters, no significant differences were detected $(\mathrm{p}>0.05)$. Data are illustrated at table (7).

Table 7:-Weight, BMI and laboratory parameters in the two studied groups (at 12 months postoperative).

\begin{tabular}{|l|c|c|c|}
\hline \multicolumn{1}{|c|}{ Items } & $\begin{array}{c}\text { Open loop duodenal switch } \\
\mathrm{n}=25\end{array}$ & $\begin{array}{c}\text { Mini gastric bypass } \\
\mathrm{n}=25\end{array}$ & P value \\
\hline Weight $(\mathrm{kg})$ & $105.28 \pm 2.28$ & $117.16 \pm 2.72$ & $<0.001^{*}$ \\
\hline BMI $\left(\mathrm{Kg} / \mathrm{m}^{2}\right)$ & $38.27 \pm 3.98$ & $42.33 \pm 3.19$ & $0.029^{*}$ \\
\hline Albumin & $4.65 \pm 0.58$ & $4.28 \pm 0.98$ & 0.125 \\
\hline LDL & $133.47 \pm 30.66$ & $135.38 \pm 32.73$ & 0.271 \\
\hline HDL & $62.38 \pm 10.48$ & $55.25 \pm 11.27$ & $0.011^{*}$ \\
\hline TGs & $147.27 \pm 33.29$ & $155.78 \pm 37.29$ & 0.287 \\
\hline Cholesterol & $127.28 \pm 19.84$ & $132.27 \pm 18.36$ & 0.118 \\
\hline HbA1C & $5.06 \pm 1.32$ & $6.18 \pm 1.22$ & $0.008^{*}$ \\
\hline Bilirubin & $0.87 \pm 0.19$ & $0.89 \pm 0.21$ & 0.629 \\
\hline Calcium & $9.86 \pm 0.18$ & $9.11 \pm 0.23$ & 0.187 \\
\hline
\end{tabular}

\section{Post-operative complications}

DS groups experienced no leaks, post-discharge admission, reoperation, or mortality. Nevertheless, 2 patients (8\%) developed incisional hernia.

Post-operative complications are illustrated in the following table. Post-operative leakage occurred in one patient in the MGB group. This patient presented one week after discharge with fever, tachycardia, and acute abdominal pain investigation was done and show leukocytosis and electrolyte imbalance. Besides, abdominal sonography showed free fluid in the abdomen. Open laparotomy was done revealing turbid fluid and pus in the peritoneal cavity for which aspiration was done, disruption of the gastro-jejunostomy was detected. The decision was to undo the operation. The jejunal loop was separated from the gastric pouch and repair was done to the anastomotic site. The lower part of the gastric pouch was resected and gastro-gastrotomy was done (minigastroplasty) with feeding jejunostomy. Then the patient was admitted to the intensive care unit and died.

In the MGB group 2 patients was admitted in the post-operative period. One case due to leak and the other patient was admitted 6 months after operation due to malnutrition in the form of hypoalbuminemea and the patient received treatment in the inpatient ward in the form of iv fluids, electrolyte, iv plasma and iv albumin and the patient was discharged 1 week later. These complications are shown at table (8).

Table 8:-Analysis of complication in the two studied groups.

\begin{tabular}{|l|c|c|c|}
\hline \multicolumn{1}{|c|}{ Items } & $\begin{array}{c}\text { Open loop duodenal switch } \\
\mathrm{n}=25\end{array}$ & $\begin{array}{c}\text { Mini gastric bypass } \\
\mathrm{n}=25\end{array}$ & $\begin{array}{c}\text { Test of } \\
\text { significance }\end{array}$ \\
\hline Readmission & $0(0 \%)$ & $2(8 \%)$ & \multirow{2}{*}{0.092} \\
\hline Leak & $0(0 \%)$ & $1(4 \%)$ & \\
\hline Reoperation & $0(0 \%)$ & $1(4 \%)$ & \\
\hline
\end{tabular}




\begin{tabular}{|l|c|c|c|}
\hline Death & $0(0 \%)$ & $1(4 \%)$ & \\
\hline Incisional /port site hernia & $2(8 \%)$ & $0(0 \%)$ & \\
\hline
\end{tabular}

\section{Outcomes in diabetic patients}

DS group showed significantly better results regarding diabetic outcomes when compared to the other group ( $\mathrm{p}<$ $0.001)$. Full remission was detected in 10 patients $(66.67 \%)$ in DS group, while only 4 patients $(40 \%)$ experienced that result in the MGB group. Diabetes control and improvement were experienced in 3 patients (20\%) and 2 patients (13.3\%) in DS group, as well as 4 patients (40\%) and 2 patients (20\%) in MGB group. Table (9) illustrates these data.

Table 9:-Analysis of outcomes in diabetic patients in the two studied groups.

\begin{tabular}{|l|c|c|c|}
\hline \multicolumn{1}{|c|}{ Items } & $\begin{array}{c}\text { Open loop duodenal switch } \\
\mathrm{n}=15\end{array}$ & $\begin{array}{c}\text { Mini gastric bypass } \\
\mathrm{n}=10\end{array}$ & $\begin{array}{c}\text { Test of } \\
\text { significance }\end{array}$ \\
\hline Diabetes outcomes & \multicolumn{2}{|c|}{$<0.001^{*}$} \\
\cline { 1 - 3 } Diabetes full remission & $10(66.67 \%)$ & $4(40 \%)$ & \\
\hline Diabetes control & $3(20 \%)$ & $4(40 \%)$ & \\
\hline $\begin{array}{l}\text { Diabetes full } \\
\text { improvement }\end{array}$ & $2(13.3 \%)$ & $2(20 \%)$ & \\
\hline
\end{tabular}

Outcomes in hypertensive patients

Regarding hypertensive patients, no significant difference was detected between the two groups $(\mathrm{p}=1)$. Four patients (33.33\%) experienced relief of hypertension in DS group, compared to 3 patients $(33.33 \%)$ in the other group. Table (10) illustrates this data.

Table 10:-Analysis of outcomes in hypertensive patients in the two studied groups.

\begin{tabular}{|c|c|c|c|}
\hline Items & $\begin{array}{c}\text { Open loop duodenal switch } \\
\mathrm{n}=12\end{array}$ & $\begin{array}{c}\text { Mini gastric bypass } \\
\mathrm{n}=9\end{array}$ & $\begin{array}{c}\text { Test of } \\
\text { significance }\end{array}$ \\
\hline Relief of HTN & $4(33.33 \%)$ & $3(33.33 \%)$ & 1 \\
\hline
\end{tabular}

\section{Outcomes in OSA patients}

All OSA experienced full improvement after surgery in both groups $(\mathrm{p}=1)$. These data are illustrated in table (11).

Table 11:-Analysis of outcomes in patients with OSA in the two studied groups.

\begin{tabular}{|c|c|c|c|}
\hline \multicolumn{1}{|c|}{ Items } & $\begin{array}{c}\text { Open loop duodenal switch } \\
\mathrm{n}=2\end{array}$ & $\begin{array}{c}\text { Mini gastric bypass } \\
\mathrm{n}=3\end{array}$ & $\begin{array}{c}\text { Test of } \\
\text { significance }\end{array}$ \\
\hline Relief of OSA & $2(100 \%)$ & $3(100 \%)$ & 1 \\
\hline
\end{tabular}

\section{Discussion:-}

1. BPD/DS procedure was found to be superior to all other bariatric procedures as reported by Buchwald's landmark meta-analysis as it achieved $70.1 \%$ excess weight loss, as compared to $61.2 \%$ and $45 \%$ for gastric bypass and adjustable gastric banding respectively. Of note, this superiority is more noticed in superobese individuals ${ }^{16-18}$.

2. Since the first Mini-Gastric Bypass (MGB) was performed by Dr. Robert Rutledge in 1997, the MGB has had a long and circuitous route from conception to widespread adoption. Much of the 20-year gestation of the MGB was related to misunderstanding and confusion of some basics of general surgery, their application and the specific technique of the MGB. There is now recognition of the MGB as a good and maybe the best form of bariatric surgery ${ }^{19}$.

3. This study was conducted at Mansoura University Hospitals aiming to compare between the outcomes of loop duodenal switch and minigastric bypass in obese individuals. A total of 50 obese patients were included in the study and they were divided into two groups, each includes 25 patients.

4. In the current study, the mean age of the included patients was 34.76 and 36.0 years for DS and MGB groups respectively. No statistically significant difference was found between both groups $(\mathrm{p}=0.622)$.

5. In another study that evaluated the role of loop DS in obese individuals, The mean age of the included patients was 50 years (range, $21-71$ years) ${ }^{20}$. In another study that compared the effects of gastric bypass to loop DS, the mean age of the included patients in DS group was $51.9 \pm 13$ years ${ }^{21}$. 
6. Deitel and Kular conducted a consensus on minigastric bypass surgery in 2018. The mean age of the collected patients was 43.5 years ${ }^{22}$.

7. In the current study, the mean BMI of the included patients was 52.59 and $51.6 \mathrm{~kg} / \mathrm{m}^{2}$ for both groups respectively. When dividing each group according to BMI, each group included 15 patients (60\%) with BMI between $50-60 \mathrm{~kg} / \mathrm{m}^{2}$, and the remaining 10 patients (40\%) were having BMI of $40-50 \mathrm{~kg} / \mathrm{m}^{2}$. No significant statistical difference was detected between the two groups regarding BMI in our study.

8. In another study that evaluated the safety and efficacy of loop DS, the mean BMI of the included patients was $57.3+9.2 \mathrm{~kg} / \mathrm{m}^{2} 23$.

9. Magouliotis and his associates compared the effects of minigastric bypass to Roux-en-Y procedure. The mean BMI of the included patients for MGB was $43.8 \mathrm{~kg} / \mathrm{m}^{22}$.

10. In our study, in each group, 20 females (80\%) as well as 5 males (20\%) were included. Therefore, gender did not constitute a difference between the two study groups $(\mathrm{p}>0.05)$.

11. In another study, MGB group included 60 males $(66.7 \%)$ in addition to 30 females $(33.3 \%){ }^{25}$. Conversely, included 32 males (27\%) and 85 females (73\%) in the MGB group ${ }^{26}$.

12. Dijkhorst and his colleagues included 55 females and 10 males in loop DS group in their study ${ }^{27}$.

13. In the current study, the mean weights of the included patients were 146.56 and $140.69 \mathrm{~kg}$ for both groups respectively $(\mathrm{p}=0.112)$.

14. Cottam and his colleagues included Loop DS patients with mean weight of $292.7 \mathrm{~kg}^{21}$. In another study that reviewed MGB procedure, the mean weight of included patients was $121.2 \mathrm{~kg}{ }^{26}$.

15. Regarding comorbidities in our study, DS group included 15 patients with diabetes (60\%) as well as 12 patients with hypertension (48\%). On the other hand, MGB group included 10 diabetic patients (40\%) in addition to 9 hypertensive patients (36\%). Besides, OSA was in $8 \%$ and $12 \%$ of patients in both groups respectively, while arthritis was reported in $4 \%$ of patients in each group.

16. Furthermore, 4 patients presented with gall bladder stones 1 case in the SADI-S group and underwent cholecystectomy with the duodenal switch and 3 patients in the MGB group 2 of them underwent cholecystectomy with the operation. Neither of the previously reported comorbidities was found to be significantly different between the two groups $(\mathrm{p}=085)$.

17. Moon et al. reported the prevalence of comorbidities in their included loop DS patients as follows, hypertension in 62 patients (44.3\%), diabetes in 39 patients (27.9\%), sleep apnea in 38 patients (27.1\%), and hyperlipidemia in 33 patients $(23.6 \%)^{23}$.

18. Carbajo and his colleagues included 180 patients (15\%) with diabetes in their series handling MGB surgery. Moreover, hypertension was present in 387 patients (32\%) while sleep apnea was present in 1113 patients (93\%). Osteoarthritis and dyslipidemia were present in $85 \%$ and $56 \%$ of the included patients respectively ${ }^{28}$.

19. Regarding lipid profile in the current study, the men values of LDL, HDL, TGs, and cholesterol in loop DS group were $164.27,36.98,204.73$, and $237.92 \mathrm{mg} / \mathrm{dl}$ respectively. On the other hand, the mean values for the same parameters for the other group were $159.37,38.94,208.22$, and $246.18 \mathrm{mg} / \mathrm{dl}$ respectively. No significant difference was detected between these baseline parameters ( $\mathrm{p}>0.05)$.

20. In another study that handles loop DS patients, the mean values of these lipid profile constituents were 98.7, 46.6, 205.0, and $185.0 \mathrm{mg} / \mathrm{dl}$ respectively ${ }^{20}$.

21. In our study, operative time was significantly longer for MGB group (155.08 vs. 71.12 minutes for DS group $\mathrm{p}<0.001$ ). This can be explained by that MGB patients were done via the laparoscopic approach while DS patients were performed via the open one.

22. It was reported that operative time for loop DS was 84 minutes (range, 40-199) in one study ${ }^{27}$. Conversely, the mean operative time for MGB was reported to be 55 minutes in another study ${ }^{25}$.

23. Regarding post-operative complications in our patients, DS group reported 2 patients of incisional hernia in the midline scar $(8 \%)$ while leakage, readmission, mortality, and reoperation were not reported. When it comes to MGB patients, 2 patients (8\%) were admitted in the post-operative period. One case due to leak and the other patient was admitted 6 months after operation due to malnutrition in the form of hypoalbuminemea and the patient received treatment in the inpatient ward in the form of iv fluids, electrolyte, iv plasma and iv albumin and the patient was discharged 1 week later. The only reported mortality case was reported in MGB group in the patient who had leakage and reoperation.

24. Dijkhorst and his associates reported that short-term complications occurred in 4 patients in loop DS group (6.1\%). Three patients required admission, from whom, 1 case was explored revealing intraperitoneal abscess with no evidence of leakage. No incisional or port site hernias were reported on the long term follow up ${ }^{27}$

25. In another study handling loop DS, there was one anastomotic leak, one patient was reoperated for hemoperitoneum and one patient was reoperated for an incarcerated umbilical hernia ${ }^{20}$. 
26. Deitel and Kular reported that leakage was reported in $0.4 \%$ of the included patients of MGB procedures. Moreover, 30-day mortality was $0.03 \%$ in the same study ${ }^{22}$. Only Kular, with his analysis on 1054 patients who underwent MGB, found a lower rate for this complication $(0.1 \%)^{29}$.

27. When it comes to weight loss and BMI changes in the current study, mean patient weight decreased down to 128.92, 117.63, and 105.28 kg after 3, 6, and 12 months in DS group. In the MGB group, mean weight decreased to $133.75,124.14,117.16 \mathrm{~kg}$ at the same time intervals respectively.

28. BMI decreased to 48.45, 43.01, and $38.27 \mathrm{~kg} / \mathrm{m} 2$ in DS group while the other group showed a decrease down to $49.35,46.89$, and $42.33 \mathrm{~kg} / \mathrm{m} 2$ at the previously reported time intervals in order of speech. It was evident that 6and 12-month changes were significantly better in Ds group when compared to MGB group (p < 0.05$)$.

29. Percentage total body weight loss (\% TBWL) following loop DS surgery was reported to have a mean of 11.3 , 16.5 , and $21.5 \%$ after 3,6 , and 12 months following the operation ${ }^{27}$.

30. Another study has reported that percentage of excess weight loss was 38.5 and $62.4 \%$ after 6 and 12 months after DS respectively. Moreover, percentage of excess body mass index loss was 41.9 and $68.1 \%$ at the same time intervals. Furthermore, total percentage of weight loss was reported to be 23.1 and $37.1 \%$ respectively ${ }^{23}$.

31. The pooled percentage of excess weight loss after SADIS ranges from $17.8 \%$ in the first 3 months up to $100 \%$ after 2 years. SADIS has shown comparable weight loss to that of RYGB ${ }^{21}$ but a superior effect than LSG $^{30}$.

32. Bhandari and his colleagues reported that percentage total weight loss was 28.75 and $33.03 \%$ after 6 and 12 months respectively following MGB surgery. Besides, percentage excess weight loss was 65.23 and $74.88 \%$ at the same time intervals respectively ${ }^{25}$.

33. In our study, lipid profile components showed a marked improvement in both groups after surgery. Nevertheless, HDL had significantly higher values in the DS group after 6 and 12 months $(\mathrm{p}<0.05)$.

34. Two years following MGB, the resolution rate in a published series was $80.6 \%$ for dyslipidemia. After 5 years, the rate of hyperlipemia decreased from 25 to 5\%. In India, hyperlipemia resolution rate at 5 years was $90 \%$ after $\mathrm{MGB}$ and $72 \%$ after $\mathrm{SG}^{31}$.

35. On the other hand, an improvement of hyperlipidemia was reported to occur in $99 \%$ of patients who underwent duodenal switch procedure ${ }^{16}$.

36. Regarding diabetes outcomes in the current study, DS group experienced significantly better results regarding diabetic outcomes when compared to the other group $(\mathrm{p}<0.001)$. Full remission was detected in 10 patients $(66.67 \%)$ in DS group, while only 4 patients $(40 \%)$ experienced that result in the MGB group. Diabetes control and improvement were experienced in 3 patients $(20 \%)$ and 2 patients $(13.3 \%)$ in DS group, as well as 4 patients $(40 \%)$ and 2 patients $(20 \%)$ in MGB group.

37. In the study conducted by Sánchez-Pernaute and his associates, loop DS has revealed an overall remission rate was $71.6 \%$ after the first postoperative year, $92.5 \%$ for patients initially under oral antidiabetic treatment and $47 \%$ for those under insulin therapy. After the second, third, fourth, and fifth postoperative years these numbers were $77 \%$ (97\% and 54\% respectively), $75.8 \%$ (96.4\% and 56\%), 63.3\% (85.7\% and $47.3 \%)$ and $52 \%(75 \%$ and $38.4 \%$ ). Most patients who achieved remission (89\%) acquired it in the first postoperative year. After an initial remission only 4 patients recurred in the first 5 years ${ }^{20}$.

38. Mingrone et al. conducted a randomized study that included 60 morbidly obese patients with T2DM. They compared the effect of medical therapy (lifestyle modifications and hypoglycemic agents) to surgical intervention (RYGB or BPD). No diabetes remission was reported in the medical group whereas $75 \%$ and $95 \%$ of patients developed diabetic remission in the RYGB and BPD groups after 2-year follow-up respectively ${ }^{32}$.

39. Supportively, both Iaconelli et al.'s included 50 patients in their uncontrolled series and Tsoli et al.'s included 24 patients in their nonrandomized trial. Both showed resolution of T2DM in all BPD patients 1 year after operation ${ }^{33,34}$. Another systematic review and metaanalysis confirmed that best diabetes resolution rate can be achieved after DS, followed by RYGB and gastric banding in order of speech ${ }^{35}$.

40. Astiarraga et al. recently assessed the effect of BPD/DS on T2DM in nonobese patients demonstrating marked amelioration (improved glycemia) of metabolic control and remission (HbA1C $<6.5 \%$ and normal oral glucose tolerance test) in 1/3 of patients, suggesting a weight independent effect of the operation, as only modest weight loss $\left(-12 \mathrm{~kg}\right.$ at 2 months, $-14 \mathrm{~kg}$ at 1 year) was observed in this nonobese patient population ${ }^{36}$.

41. Regarding MGB, the reported rate of type II diabetes resolution was about $85.9-91.5 \%$ after 1 year whereas this rate showed some decline at 5-year follow up $(79.8-90.1 \%)^{22}$. Another study reported that the rate of diabetes resolution was $61.9 \%$ following MGB and it was not significant when compared to Roux en Y bypass 25 .

42. The MGB and OAGB have been documented to be dependable bariatric operations in large series ${ }^{37}$. They have shown superiority in resolution of comorbidities, in comparative studies to the RYGB and SG ${ }^{38}$. Furthermore, the MGB and OAGB have resulted in resolution of T2D in 85-95\% of diabetics followed >5 years, requiring no 
medication ${ }^{39}$, which is superior to more complex operations. In a careful study, Jammu reported resolution of T2D in $94.7 \%$ of Punjabi diabetics ${ }^{40}$. Following MGB with the rapid passage of food contents into lower bowel, significant rapid elevation in levels of GLP-1 has been found, compared to the other operations ${ }^{41}$.

43. Lee et al. found that MGB and SG can rapidly augment the incretin effect, which persists up to 5 years. However, they demonstrated that MGB had a significantly better incretin effect than SG at longer follow-up. The improvement of the incretin effect is explained by the increase of GLP-1 serum levels ${ }^{42}$.

44. In our study, regarding hypertensive patients, no significant difference was detected between the two groups ( $p$ $=1$ ). Four patients $(33.33 \%)$ experienced relief of hypertension in DS group, compared to 3 patients (33.33\%) in the other group.

45. Resolution of hypertension after MGB was reported to be ranging between $76.8-80.6 \%$ after 1 year. Besides, this resolution rate declined 5 years after surgery $(69-78.6 \%)^{22}$.

46. In addition to added benefit of superior weight loss in patients undergoing DS, patients also enjoy higher frequency of improvement of resolution of comorbidities such as hypertension, and sleep apnea as reported in a previous report ${ }^{43}$.

47. All OSA patients $(100 \%)$ experienced full improvement after surgery in our study in both groups $(\mathrm{p}=1)$.

48. The reported resolution of OSA after MGB was reported to range between $87.0-95.4 \%$ after 1 year. At 5-year follow up, OSA resolution has been reported to be $86.7-93.2 \%$.

49. Buchwald and colleagues, in a meta-analysis of 32 studies with 4035 patients who underwent a biliopancreatic diversion or BPD-DS, reported that BPD-DS is the surgery offering the best long-term excess weight loss (EWL of 70\%), improvement or remission of T2DM in 98\%, resolution of hypertension in $81 \%$, resolution of sleep apnea in $95 \%$, and improvement of hyperlipidemia in $99 \%{ }^{16}$.

50. The main drawback of this study is that included a small sample size ( $\mathrm{n}=25$ patients). Furthermore, the follow up of the patients included short and medium term only. As a result, more studies including larger number of patients with longer follow up periods should be conducted in the future.

\section{Conclusion:-}

Based on the results of the current study, it was evident that both loop duodenal switch and minigastric bypass procedures are effective in the management of morbid obesity and its related comorbidities. However, loop DS operation is more effective in weight loss when compared to MGB.

\section{References:-}

1. Prachand V.N., DaVee R.T., and Alverdy J.C. Duodenal switch provides superior weight loss in the superobese (BMI $\geq 50 \mathrm{~kg} / \mathrm{m} 2)$ compared with gastric bypass. Annals of surgery 2006, 244 (4), 611.

2. Ogden C.L., Carroll M.D., Curtin L.R., McDowell M.A., Tabak C.J., and Flegal K.M. Prevalence of overweight and obesity in the United States, 1999-2004. Jama 2006, 295 (13), 1549-1555.

3. Sturm R. Increases in morbid obesity in the USA: 2000-2005. Public health 2007, 121 (7), 492-496.

4. Williams E.P., Mesidor M., Winters K., Dubbert P.M., and Wyatt S.B. Overweight and obesity: prevalence, consequences, and causes of a growing public health problem. Current obesity reports 2015, 4 (3), 363-370.

5. DeMaria E.J., Pate V., Warthen M., and Winegar D.A. Baseline data from American society for metabolic and bariatric surgery-designated bariatric surgery centers of excellence using the bariatric outcomes longitudinal database. Surgery for Obesity and Related Diseases 2010, 6 (4), 347-355.

6. Jammu G.S. and Sharma R. A 7-year clinical audit of 1107 patients comparing sleeve gastrectomy, Roux-En-Y gastric bypass, and mini-gastric bypass, to determine an effective and safe bariatric and metabolic procedure. Obesity surgery 2016, 26 (5), 926-932.

7. Scopinaro N., Gianetta E., Civalleri D., Bonalumi U., and Bachi V. Bilio-pancreatic bypass for obesity: II. Initial experience in man. British Journal of Surgery 1979, 66 (9), 618-620.

8. Rubino F. and Marescaux J. Effect of duodenal-jejunal exclusion in a non-obese animal model of type 2 diabetes: a new perspective for an old disease. Annals of surgery 2004, 239 (1), 1.

9. Sánchez-Pernaute A., Herrera M.A.R., Pérez-Aguirre M.E., Talavera P., Cabrerizo L., Matía P., DíezValladares L., Barabash A., Martín-Antona E., and García-Botella A. Single anastomosis duodeno-ileal bypass with sleeve gastrectomy (SADI-S). One to three-year follow-up. Obesity surgery 2010, 20 (12), 1720-1726.

10. Marceau P., Biron S., Bourque R.-A., Potvin M., Hould F.-S., and Simard S. Biliopancreatic diversion with a new type of gastrectomy. Obesity surgery 1993, 3 (1), 29-35. 
11. Padwal R., Klarenbach S., Wiebe N., Birch D., Karmali S., Manns B., Hazel M., Sharma A., and Tonelli M. Bariatric surgery: a systematic review and network meta-analysis of randomized trials. Obesity Reviews 2011, $12(8), 602-621$.

12. Weiner J.P., Goodwin S.M., Chang H.-Y., Bolen S.D., Richards T.M., Johns R.A., Momin S.R., and Clark J.M. Impact of bariatric surgery on health care costs of obese persons: a 6-year follow-up of surgical and comparison cohorts using health plan data. JAMA surgery 2013, 148 (6), 555-561.

13. Mahawar K.K., Jennings N., Brown J., Gupta A., Balupuri S., and Small P.K. "Mini” gastric bypass: systematic review of a controversial procedure. Obesity surgery 2013, 23 (11), 1890-1898.

14. Noun R., Skaff J., Riachi E., Daher R., Antoun N.A., and Nasr M. One thousand consecutive mini-gastric bypass: short-and long-term outcome. Obesity surgery 2012, 22 (5), 697-703.

15. Rutledge R., Kular K., Marchanda N., Bandari M., and Goel R. A comparison of the outcomes of revision of the Roux-en-Y (RNY) and mini-gastric bypass (MGB); hard vs. easy. Eur J Endosc Laparosc Surg 2014, 1, 1-6.

16. Buchwald H., Avidor Y., Braunwald E., Jensen M.D., Pories W., Fahrbach K., and Schoelles K. Bariatric surgery: a systematic review and meta-analysis. Jama 2004, 292 (14), 1724-1737.

17. Afaneh C. and Pomp A.; Duodenal Switch: Technique and Outcomes, in The SAGES Manual of Bariatric Surgery 2018, Springer. p. 327-338.

18. Abd-Elatif A., Youssef T., Farid M., Ali Y., and Gado W. Nutritional markers after loop duodenal switch (SADI-S) for morbid obesity: a technique with favorable nutritional outcome. J Obes Weight Loss Ther 2015, 5 (3), 1000268.

19. Musella M., Susa A., Manno E., De Luca M., Greco F., Raffaelli M., Cristiano S., Milone M., Bianco P., and Vilardi A. Complications following the mini/one anastomosis gastric bypass (MGB/OAGB): a multiinstitutional survey on 2678 patients with a mid-term (5 years) follow-up. Obesity surgery 2017, 27 (11), 29562967.

20. Sánchez-Pernaute A., Rubio M.Á., Cabrerizo L., Ramos-Levi A., Pérez-Aguirre E., and Torres A. Singleanastomosis duodenoileal bypass with sleeve gastrectomy (SADI-S) for obese diabetic patients. Surgery for Obesity and Related Diseases 2015, 11 (5), 1092-1098.

21. Cottam A., Cottam D., Medlin W., Richards C., Cottam S., Zaveri H., and Surve A. A matched cohort analysis of single anastomosis loop duodenal switch versus Roux-en-Y gastric bypass with 18-month follow-up. Surgical endoscopy 2016, 30 (9), 3958-3964.

22. Deitel M. and Kular K.S. Consensus survey on mini-gastric bypass and one-anastomosis gastric bypass. Ann Bariatr Metab Surg 2018, 1, 1001.

23. Moon R.C., Gaskins L., Teixeira A.F., and Jawad M.A. Safety and effectiveness of single-anastomosis duodenal switch procedure: 2-year result from a single US institution. Obesity surgery 2018, 28 (6), 1571-1577.

24. Magouliotis D., Tasiopoulou V., and Tzovaras G. One anastomosis gastric bypass versus Roux-en-Y gastric bypass for morbid obesity: a meta-analysis. Clinical obesity 2018, 8 (3), 159-169.

25. Bhandari M., Nautiyal H.K., Kosta S., Mathur W., and Fobi M. Comparison of One anastomosis gastric bypass (OAGB) and Roux-en-Y gastric bypass (RYGB) for Treatment of Obesity: A Five-Year Study. Surgery for Obesity and Related Diseases 2019.

26. Robert M., Espalieu P., Pelascini E., Caiazzo R., Sterkers A., Khamphommala L., Poghosyan T., Chevallier J.M., Malherbe V., and Chouillard E. Efficacy and safety of one anastomosis gastric bypass versus Roux-en-Y gastric bypass for obesity (YOMEGA): a multicentre, randomised, open-label, non-inferiority trial. The Lancet 2019, 393 (10178), 1299-1309.

27. Dijkhorst P.J., Boerboom A.B., Janssen I.M., Swank D.J., Wiezer R.M., Hazebroek E.J., Berends F.J., and Aarts E.O. Failed sleeve gastrectomy: single anastomosis duodenoileal bypass or Roux-en-Y gastric bypass? A multicenter cohort study. Obesity surgery 2018, 28 (12), 3834-3842.

28. Carbajo M.A., Luque-de-León E., Jiménez J.M., Ortiz-de-Solórzano J., Pérez-Miranda M., and Castro-Alija M.J. Laparoscopic one-anastomosis gastric bypass: technique, results, and long-term follow-up in 1200 patients. Obesity surgery 2017, 27 (5), 1153-1167.

29. Kular K., Manchanda N., and Rutledge R. A 6-year experience with 1,054 mini-gastric bypasses-first study from Indian subcontinent. Obesity surgery 2014, 24 (9), 1430-1435.

30. Cottam A., Cottam D., Roslin M., Cottam S., Medlin W., Richards C., Surve A., and Zaveri H. A matched cohort analysis of sleeve gastrectomy with and without $300 \mathrm{~cm}$ loop duodenal switch with 18-month follow-up. Obesity surgery 2016, 26 (10), 2363-2369.

31. Chevallier J.-M.; Effects of MGB on Obesity-Related Co-Morbidities: Lipids, Hypertension, Non-Alcoholic Fatty Liver, etc, in Essentials of Mini-One Anastomosis Gastric Bypass 2018, Springer. p. 111-117. 
32. Mingrone G., Panunzi S., De Gaetano A., Guidone C., Iaconelli A., Leccesi L., Nanni G., Pomp A., Castagneto M., and Ghirlanda G. Bariatric surgery versus conventional medical therapy for type 2 diabetes. New England Journal of Medicine 2012, 366 (17), 1577-1585.

33. Iaconelli A., Panunzi S., De Gaetano A., Manco M., Guidone C., Leccesi L., Gniuli D., Nanni G., Castagneto M., and Ghirlanda G. Effects of bilio-pancreatic diversion on diabetic complications: a 10-year follow-up. Diabetes care 2011, 34 (3), 561-567.

34. Tsoli M., Chronaiou A., Kehagias I., Kalfarentzos F., and Alexandrides T.K. Hormone changes and diabetes resolution after biliopancreatic diversion and laparoscopic sleeve gastrectomy: a comparative prospective study. Surgery for Obesity and Related Diseases 2013, 9 (5), 667-677.

35. Buchwald H., Estok R., Fahrbach K., Banel D., Jensen M.D., Pories W.J., Bantle J.P., and Sledge I. Weight and type 2 diabetes after bariatric surgery: systematic review and meta-analysis. The American journal of medicine 2009, 122 (3), 248-256. e5.

36. Astiarraga B., Gastaldelli A., Muscelli E., Baldi S., Camastra S., Mari A., Papadia F., Camerini G., Adami G., and Scopinaro N. Biliopancreatic diversion in nonobese patients with type 2 diabetes: impact and mechanisms. The Journal of Clinical Endocrinology \& Metabolism 2013, 98 (7), 2765-2773.

37. Deitel M., Hargroder D., and Peraglie C. Mini-gastric bypass for bariatric surgery increasing worldwide. Austin J Surg 2016, 3 (3), 1092-1096.

38. Luciani R.C.; The MGB-OAGB International Club®, in Essentials of Mini-One Anastomosis Gastric Bypass 2018, Springer. p. 355-360.

39. 39. Forieg A.M.; Effects of MGB on Type 2 Diabetes in Morbid Obesity, and Comparison with Other Operations, in Essentials of Mini-One Anastomosis Gastric Bypass 2018, Springer. p. 119-130.

40. Jammu G.S. and Sharma R. An eight-year experience with 189 Type 2 diabetic patients after mini-gastric bypass. Integr Obes Diabetes 2016, 2 (4), 246-249.

41. Kim M.J., Park H.K., Byun D.W., Suh K.I., and Hur K.Y. Incretin levels 1 month after laparoscopic single anastomosis gastric bypass surgery in non-morbid obese type 2 diabetes patients. Asian journal of surgery 2014, 37 (3), 130-137.

42. Lee W.-J., Chong K., Lin Y.-H., Wei J.-H., and Chen S.-C. Laparoscopic sleeve gastrectomy versus single anastomosis (mini-) gastric bypass for the treatment of type 2 diabetes mellitus: 5 -year results of a randomized trial and study of incretin effect. Obesity surgery 2014, 24 (9), 1552-1562.

43. Prachand V.N. and Hussain M.; Duodenal Switch: Technique and Outcomes, in The ASMBS Textbook of Bariatric Surgery 2015, Springer. p. 211-220. 